\title{
ANALISA METODE DATA MINING PADA PENGELOMPOKAN LAPANGAN KERJA INFORMAL SEKTOR NON-PERTANIAN
}

\author{
Khairunnissa Fanny Irnanda ${ }^{1}$, Agus Perdana Windarto ${ }^{2}$, Dedy Hartama ${ }^{3}$, Anjar Wanto ${ }^{4}$ \\ ${ }^{1,2,3,4}$ Sistem Informasi, STIKOM Tunas Bangsa, Pematangsiantar, Indonesia \\ Email: ${ }^{1}$ nissafanny@gmail.com, ${ }^{2}$ agus.perdana@amiktunasbangsa.ac.id
}

\begin{abstract}
Abstrak
Penelitian ini bertujuan untuk mengelompokkan lapangan kerja informal dalam sektor non-pertanian. Sumber data diperoleh dari Badan Pusat Statistik (BPS). Data yang digunakan adalah data proporsi lapangan kerja informal sektor non-pertanian (2015-2018) yang terdiri dari 34 wilayah di Indonesia. Metode yang digunakan untuk meyelesaikan permasalahan tersebut dengan teknik datamining yaitu K-Medoid. Hasil dari penelitian menunjukkan bahwa persentase proporsi lapangan kerja informal sektor nonpertanian berdasarkan wilayah yang terendah menjadi catatan bagi pemerintah agar lebih meningkatkan sumber daya manusianya dan lebih banyak membukakan lapangan pekerjaan dalam sektor non-pertanian, Adapun wilayah tersebut antara lain : Sumatera Barat, Lampung, Jawa Tengah, Jawa Timur, Nusa Tenggara Barat, Nusa Tenggara Timur, Kalimantan Selatan, Gorontalo dan Sulawesi Barat.
\end{abstract}

Kata kunci: Sektor Informal, Datamining, K-Medoid, Clustering, Non-Pertanian

\begin{abstract}
The objective of the study is to classify informal employment in non-agricultural sectors. Data sources are obtained from the Central Statistics Agency (BPS). The data used is the proportion of employment for informal non-agricultural sectors (2015-2018), consisting of 34 Provinces in Indonesia. The Method used to solve the problem is datamining technique K-Medoid. The results of the research showed that the percentage of informal employment of non-agricultural sectors based on the lowest region became a record for the government to further increase human resources and more open the field jobs in non-agricultural sectors, among others.
\end{abstract}

Keywords: Informal sector, Datamining, K-Medoid, Clustering, Non-Agricultural

\section{PENDAHULUAN}

Sektor informal adalah sektor ekonomi yang terdiri atas unit usaha berskala kecil, yang memproduksi dan mendistribusikan barang dan jasa, dengan tujuan utama menciptakan kesempatan kerja dan kesempatan memperoleh pendapatan bagi para pelakunya. Sektor informal identik dengan ketidakorganisiran (unorganized), ketidakteraturan (unregulated), tidak terdaftar, dan merupakan tempat bagi mereka yang berpendidikan rendah dan tidak mampu bersaing menuju posisi pekerjaan yang mapan di sektor formal [1]. Istilah sektor informal biasanya digunakan untuk menunjukkan sejumlah kegiatan ekonomi yang berskala kecil. Keberadaan dan kelangsungan kegiatan sektor informal dalam sistem ekonomi kotemporer bukanlah gejala negatif, namun lebih sebagai realitas ekonomi kerakyatan yang berperan cukup penting dalam pengembangan masyarakat dan pembangunan nasional. Setidaknya, ketika program pembangunan kurang mampu menyediakan peluang kerja bagi angkatan kerja, sektor informal dengan segala kekurangannya mampu berperan sebagai penampung dan alternatif peluang kerja bagi para pencari kerja. Gelombang ketidakpuasan kaum miskin dan para penganggur terhadap ketidakmampuan pembangunan menyediakan peluang kerja, untuk sementara dapat diredam lantaran tersedia peluang kerja di sektor informal [2]. Sampai saat ini, pengertian sektor informal sering dikaitkan dengan ciri-ciri utama pengusaha dan pelaku sektor informal, antara lain: kegiatan usaha bermodal utama pada kemandirian rakyat, memanfaatkan teknologi sederhana, pekerjanya terutama berasal dari tenaga kerja keluarga tanpa upah, bahan baku usaha kebanyakan memanfaatkan sumber daya lokal, sebagian besar melayani kebutuhan rakyat kelas menengah ke bawah, pendidikan dan kualitas sumber daya pelaku tergolong rendah [3].

Ada banyak teknik ilmu komputer yang dapat digunakan untuk menyelesaikan permasalahan kompleks. Mereka diantaranya adalah sistem pendukung keputusan [4]-[8], datamining [9]-[12], sistem pakar [13], jaringan saraf tiruan [14]-[17], algoritma genetika [18] dan lain-lain. Peneliti menggunakan teknik data mining dengan algoritma clustering. Clustering merupakan salah satu metode Data Mining yang bersifat tanpa arahan (unsupervised). Ada dua jenis data clustering yang sering dipergunakan dalam proses pengelompokan data yaitu hierarchical (hirarki) data clustering dan nonhierarchical (non hirarki) data clustering. K-Medoid merupakan proses mengelompokkan data ke dalam suatu kelompok, sehingga data pada suatu kelompok memiliki kemiripan yang sangat besar dengan data lain pada kelompok yang sama, tetapi sangat tidak mirip dengan data pada klaster lain [19]. Berdasarkan permasalahan tersebut, tujuan dari penelitian ini adalah untuk mengelompokan lapangan kerja informal sektor non-pertanian sehingga hasil dari penelitian menjadi masukan kepada pihak terkait untuk meningkatkan lapangan kerja informal sektor non-pertanian di wilayah yang memiliki klaster yang paling rendah.

\section{TEORITIS}


Dalam penelitian ini metode yang digunakan yaitu metode data mining sebagai berikut. (a) Tahap pengumpulan data, (b) Tahap pengolahan data, (c) Tahap Clustering dan (d) Tahap Analisis.

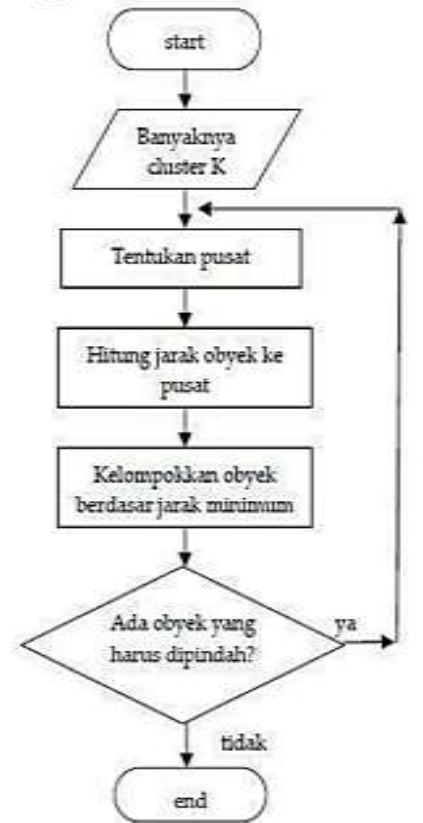

Gambar 1. Flowchat K-Medoid

\subsection{Pengumpulan Data}

Data yang dibutuhkan dalam penelitian ini adalah data proporsi lapangan kerja informal sektor non-pertanian berdasarkan provinsi yang diperoleh dari sebuah situs resmi https://www.bps.go.id . Data yang dikumpulkan berupa data proporsi lapangan kerja informal sektor non-pertanian dengan jumlah 34 provinsi dari tahun 2015 hingga 2018. Variabel yang digunakan: Proporsi lapangan kerja sektor informal non-pertanian tahun 2017 dan Proporsi lapangan kerja sektor informal non-pertanian tahun 2018.

\subsection{Pengolahan Data}

Pada pengolahan data ini penulis melakukan penglolahan data awal yang merupakan tahap untuk mempersiapkan data yang telah diperoleh sebelumnya dan akan digunakan pada tahap selanjutnya. Data yang sudah dikumpulkan akan diolah menjadi 2 cluster dengan beberapa tahap dan proses perhitungannya menggunakan bantuan aplikasi rapidminer.

\subsection{Metode Clustering}

Clustering merupakan salah satu teknik dari salah satu fungsionalitas datamining, algoritma clustering merupakan algoritma pengelompokan sejumlah data menjadi kelompok-kelompok data tertentu(cluster) [20]. Potensi clustering adalah dapat digunakan untuk mengetahui struktur dalam data yang dapat dipakai lebih lanjut dalam berbagai aplikasi secara luas seperti klasifikasi, pengolahan gambar, dan pengenalan pola. Pada proses analisis cluster metode yang digunakan untuk membagi data menjadi subset data berdasarkan kesamaan atau kemiripan yang telah ditentukan sebelumnya. Jadi analisis cluster secara umum dapat dikatakan bahwa :

1. Data yang terdapat dalam satu cluster memiliki tingkat kesamaan yang tinggi, dan

2. Dan yang terdapat dalam suatu cluster yang berbeda memiliki tingkat kesamaan yang rendah

\subsection{Algoritma K-Medoid}

Algoritma k-medoid merupakan proses mengelompokkan data ke dalam suatu kelompok, sehingga data pada suatu kelompok memiliki kemiripan yang sangat besar dengan data lain pada kelompok yang sama, tetapi sangat tidak mirip dengan data pada klaster lain. K- Medoids adalah mencari titik yang paling representatif (medoids) dalam sebuah dataset dengan menghitung jarak dalam kelompok dari semua kemungkinan kombinasi dari medoids sehingga jarak antar titik dalam suatu cluster kecil sedangkan jarak titik antar cluster besar. Algoritma K- Medoids memiliki kelebihan untuk mengatasi kelemahan pada pada algoritma K-Means yang sensitive terhadap noise dan outlier, dimana objek dengan nilai yang besar yang memungkinkan menyimpang pada dari distribusi data [21].

Langkah- langkah algoritma K-Medoids: 
1. Inisialisasi pusat cluster sebanyak $\mathrm{k}$ (jumlah cluster)

Dalam penelitian ini penulis menggunakan 2 cluster yaitu: (C1) dan (C2)

2. Alokasikan setiap data (objek) ke cluster terdekat menggunakan persamaan ukuran jarak Euclidian Distance dengan persamaan: $d=\sqrt{\sum_{i=1}^{n}(x i-y i)^{2}}$

3. Pilih secara acak objek pada masing-masing cluster sebagai kandidat medoid baru.

4. Hitung jarak setiap objek yang berada pada masing-masing cluster dengan kandidat medoid baru.

5. Hitung total simpangan $(S)$ dengan menghitung nilai total distance baru - total distance lama. Jika $S<0$, maka tukar objek dengan data cluster untuk membentuk sekumpulan k objek baru sebagai medoid.

6. Ulangi langkah 3 sampai 5 hingga tidak terjadi perubahan medoid, sehingga didapatkan cluster beserta anggota cluster masing-masing.

Adapun skema alur tahapan penelitian ini ditunjukan pada Gambar 2.

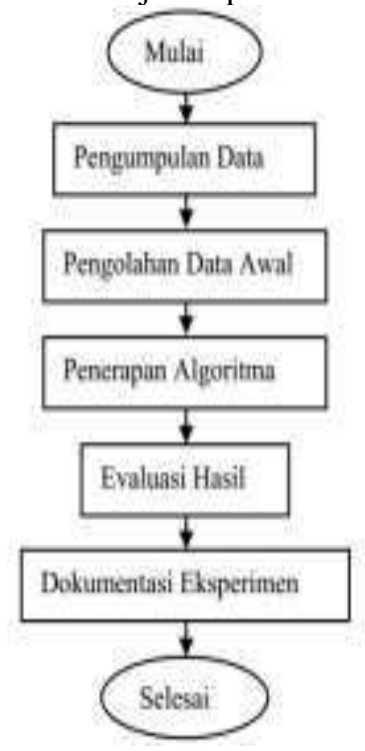

Gambar 2. Alur Tahapan Penelitian

\section{ANALISA DAN PEMBAHASAN}

Pada pengclusteran ini,data yang sudah dikumpulkan akan dihitung terlebih dahulu berdasarkan data proporsi lapangan kerja informal sektor non-pertanian dengan jumlah 34 provinsi yang ada di Indonesia yang ditunjukkan pada Tabel 1.

Tabel 1. Data Awal Proporsi Lapangan Kerja Informal Sektor Non-Pertanian

\begin{tabular}{lcccc}
\hline \multirow{2}{*}{ Provinsi } & \multicolumn{3}{c}{ Proporsi Lapangan Kerja Informal Sektor Non-Pertanian Menurut Provinsi } \\
\cline { 2 - 5 } & $\mathbf{2 0 1 5}$ & $\mathbf{2 0 1 6}$ & $\mathbf{2 0 1 7}$ & $\mathbf{2 0 1 8}$ \\
\hline Aceh & 40.51 & 41.64 & 42.27 & 42.86 \\
Sumatera Utara & 44.69 & 40.73 & 44.17 & 43.59 \\
Sumatera Barat & 50.48 & 48.31 & 50.48 & 51.26 \\
Riau & 36.04 & 37.21 & 38.73 & 41.09 \\
Jambi & 41.44 & 44.51 & 40 & 38.85 \\
Sumatera Selatan & 41.66 & 44.69 & 42.15 & 42.77 \\
Bengkulu & 44.94 & 49.79 & 44.66 & 47.22 \\
Lampung & 54.68 & 52.6 & 54.85 & 55.88 \\
Kep. Bangka Belitung & 39.92 & 45.61 & 36.13 & 38.04 \\
Kep. Riau & 22.1 & 28.3 & 27.26 & 28.65 \\
Dki Jakarta & 26.95 & 31.12 & 28.41 & 30.12 \\
Jawa Barat & 43.37 & 41.08 & 42.82 & 42.14 \\
Jawa Tengah & 50.16 & 48.85 & 49.53 & 51.02 \\
Di Yogyakarta & 38.44 & 42.54 & 45.24 & 43.95 \\
Jawa Timur & 47.9 & 45.84 & 47.34 & 47.68 \\
Banten & 30.93 & 30.33 & 34 & 36.25 \\
Bali & 41.41 & 44.02 & 39.26 & 38.62 \\
Nusa Tenggara Barat & 58.12 & 58.42 & 60.68 & 59.43 \\
Nusa Tenggara Timur & 47.68 & 48.13 & 49.96 & 49.97 \\
Kalimantan Barat & 38.47 & 40.96 & 39.02 & 36.37 \\
Kalimantan Tengah & 42.04 & 44.4 & 40.83 & 39.97
\end{tabular}




\begin{tabular}{lcccc} 
Kalimantan Selatan & 44.8 & 48.4 & 47.66 & 46.17 \\
Kalimantan Timur & 31.17 & 35.51 & 31.61 & 32.17 \\
Kalimantan Utara & 27.11 & 28.32 & 29.85 & 29.5 \\
Sulawesi Utara & 46.66 & 46.79 & 44.37 & 45.24 \\
Sulawesi Tengah & 43.62 & 44.05 & 47.26 & 46.15 \\
Sulawesi Selatan & 42.1 & 46.69 & 42.79 & 44.77 \\
Sulawesi Tenggara & 48.73 & 50.77 & 44.98 & 45.87 \\
Gorontalo & 49.76 & 46.7 & 47.63 & 49.09 \\
Sulawesi Barat & 47.21 & 48.68 & 46.72 & 53.82 \\
Maluku & 45.48 & 44.15 & 44.18 & 48.17 \\
Maluku Utara & 45.05 & 45.98 & 42.85 & 42.53 \\
Papua Barat & 37.06 & 39.3 & 41.31 & 34.85 \\
Papua & 34.57 & 39.18 & 33.8 & 34.19 \\
\hline
\end{tabular}

\subsection{Centroid Data}

Dalam penerapan algoritma K-Medoid nilai titik tengah atau centroid dapat ditentukan secara random atau acak, dari data yang didapat dengan ketentuan bahwa clusterisasi yang diinginkan adalah 2, Penentuan cluster dibagi atas dua bagian yakni cluster tingkat lapangan kerja rendah(C1)dan cluster tingkat lapangan kerja tinggi(C2), maka nilai titik tengah atau centroid juga terdapat 2 titik. Penentuan titik cluster ini dilakukan dengan mengambil nilai secara acak. Data awal akan diolah menggunakan rumus Euclidian Distance dengan centroid awal yang telah ditentukan. Berikut adalah centroid awal yang digunakan:

Tabel 2. Data Centroid awal

\begin{tabular}{lll}
\hline Kep. Riau & 27.26 & 28.65 \\
Di Yogyakarta & 45.24 & 43.95 \\
\hline
\end{tabular}

Ada pun hasil perhitungan nya sebagai berikut:

Tabel 3. Data Setelah Diolah

\begin{tabular}{|c|c|c|c|c|c|}
\hline \multirow{2}{*}{ Provinsi } & \multicolumn{2}{|c|}{ Proporsi Lapangan Kerja Informal Sektor Non-Pertanian } & \multirow{2}{*}{ C1 } & \multirow{2}{*}{ C2 } & \multirow{2}{*}{ Jarak Terpendek } \\
\hline & 2017 & 2018 & & & \\
\hline Aceh & 42.27 & 42.86 & 20.669403 & 3.163700365 & 3.163700365 \\
\hline Sumatera Utara & 44.17 & 43.59 & 22.56439 & 1.128937554 & 1.128937554 \\
\hline Sumatera Barat & 50.48 & 51.26 & 32.409574 & 8.994092506 & 8.994092506 \\
\hline Riau & 38.73 & 41.09 & 16.92083 & 7.110534438 & 7.110534438 \\
\hline Jambi & 40 & 38.85 & 16.320159 & 7.312154265 & 7.312154265 \\
\hline Sumatera Selatan & 42.15 & 42.77 & 20.520392 & 3.307642665 & 3.307642665 \\
\hline Bengkulu & 44.66 & 47.22 & 25.448082 & 3.321038994 & 3.321038994 \\
\hline Lampung & 54.85 & 55.88 & 38.76443 & 15.319171 & 15.319171 \\
\hline Kep. Bangka & & & & & \\
\hline Belitung & 36.13 & 38.04 & 12.917004 & 10.85910678 & 10.85910678 \\
\hline Kep. Riau & 27.26 & 28.65 & 0 & 23.60869331 & 0 \\
\hline Dki Jakarta & 28.41 & 30.12 & 1.8663869 & 21.78342948 & 1.866386884 \\
\hline Jawa Barat & 42.82 & 42.14 & 20.593535 & 3.022002647 & 3.022002647 \\
\hline Jawa Tengah & 49.53 & 51.02 & 31.565326 & 8.269764205 & 8.269764205 \\
\hline Di Yogyakarta & 45.24 & 43.95 & 23.608693 & 0 & 0 \\
\hline Jawa Timur & 47.34 & 47.68 & 27.664911 & 4.280525669 & 4.280525669 \\
\hline Banten & 34 & 36.25 & 10.15813 & 13.62452201 & 10.15812975 \\
\hline Bali & 39.26 & 38.62 & 15.601311 & 8.010574262 & 8.010574262 \\
\hline $\begin{array}{l}\text { Nusa Tenggara } \\
\text { Barat }\end{array}$ & 60.68 & 59.43 & 45.434621 & 21.86375997 & 21.86375997 \\
\hline Nusa Tenggara & & & & & \\
\hline Timur & 49.96 & 49.97 & 31.142132 & 7.649758166 & 7.649758166 \\
\hline Kalimantan Barat & 39.02 & 36.37 & 14.067551 & 9.805345481 & 9.805345481 \\
\hline Kalimantan Tengah & 40.83 & 39.97 & 17.671652 & 5.940412444 & 5.940412444 \\
\hline Kalimantan Selatan & 47.66 & 46.17 & 26.890712 & 3.284021924 & 3.284021924 \\
\hline Kalimantan Timur & 31.61 & 32.17 & 5.5957931 & 18.01514085 & 5.595793063 \\
\hline Kalimantan Utara & 29.85 & 29.5 & 2.7259127 & 21.11053292 & 2.725912691 \\
\hline Sulawesi Utara & 44.37 & 45.24 & 23.832335 & 1.555956298 & 1.555956298 \\
\hline Sulawesi Tengah & 47.26 & 46.15 & 26.575365 & 2.986703869 & 2.986703869 \\
\hline Sulawesi Selatan & 42.79 & 44.77 & 22.383818 & 2.583582784 & 2.583582784 \\
\hline Sulawesi Tenggara & 44.98 & 45.87 & 24.708841 & 1.937524193 & 1.937524193 \\
\hline Gorontalo & 47.63 & 49.09 & 28.85707 & 5.668483042 & 5.668483042 \\
\hline Sulawesi Barat & 46.72 & 53.82 & 31.815413 & 9.980345685 & 9.980345685 \\
\hline Maluku & 44.18 & 48.17 & 25.832476 & 4.351091817 & 4.351091817 \\
\hline Maluku Utara & 42.85 & 42.53 & 20.873488 & 2.780017986 & 2.780017986 \\
\hline Papua Barat & 41.31 & 34.85 & 15.357164 & 9.91236097 & 9.91236097 \\
\hline Papua & 33.8 & 34.19 & 8.5710676 & 15.03765939 & 8.571067611 \\
\hline
\end{tabular}




\subsection{Clustering}

Dengan menggunakan centroid tersebut maka dapat dicluster data yang telah didapat menjadi 2 cluster. Proses cluster dengan mengambil jarak terdekat dari setiap data yang diolah. Dari data awaldidapatkan pengelompokan pada iterasi luntuk 2 cluster tersebut.Pada iterasi awal pengelompokan yaitu 2 cluster yang ditunjukkan pada Tabel 4.

\begin{tabular}{|c|c|}
\hline Klaster 1 & Klaster 2 \\
\hline Kep. Riau & Aceh \\
\hline DKI Jakarta & Sumatera Utara \\
\hline Banten & Sumatera Barat \\
\hline Kalimantan Timur & Riau \\
\hline Kalimantan Utara & Jambi \\
\hline \multirow[t]{24}{*}{ Papua } & Sumatera Selatan \\
\hline & Bengkulu \\
\hline & Lampung \\
\hline & Kep. Bangka Belitung \\
\hline & Jawa Barat \\
\hline & Jawa Tengah \\
\hline & Di Yogyakarta \\
\hline & Jawa Timur \\
\hline & Bali \\
\hline & Nusa Tenggara Barat \\
\hline & Nusa Tenggara Timur \\
\hline & Kalimantan Barat \\
\hline & Kalimantan Tengah \\
\hline & Kalimantan Selatan \\
\hline & Sulawesi Utara \\
\hline & Sulawesi Tengah \\
\hline & Sulawesi Selatan \\
\hline & Sulawesi Tenggara \\
\hline & Gorontalo \\
\hline & Sulawesi Barat \\
\hline & Maluku \\
\hline & Maluku Utara \\
\hline & Papua Barat \\
\hline & Papua \\
\hline
\end{tabular}

Proses Clustering berhenti jika Simpangan $>0$, tetapi jika Simpangan $<0$ maka tukar objek dengan data cluster untuk membentuk sekumpulan k objek baru sebagai medoid. Proses perhitungan simpangan dengan cara menjumlahkan nilai total distance baru - total distance lama yang beisikan jarak setiap objek yang berada pada masing-masing cluster dengan kandidat medoid baru. Dengan jumlah simpangan yang ditunjukkan pada Tabel 5.

Tabel 5. Jumlah Distance Iterasi pertama

\begin{tabular}{cc}
\hline Klaster 1 & Klaster 2 \\
\hline 3.1637 & 0 \\
1.128938 & 1.866387 \\
8.994093 & 10.15813 \\
7.110534 & 5.595793 \\
7.312154 & 2.725913 \\
3.307643 & 8.571068 \\
3.321039 & \\
15.31917 & \\
10.85911 & \\
3.022003 & \\
8.269764 & \\
0 & \\
4.280526 & \\
8.010574 & \\
21.86376 & \\
7.649758 & \\
9.805345 & \\
5.940412 & \\
3.284022 & \\
1.555956 & \\
&
\end{tabular}




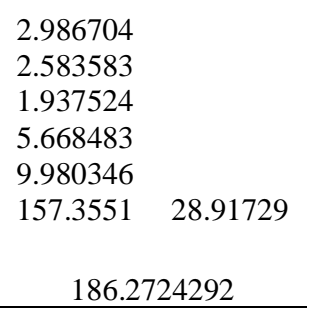

Tabel 6. Jumlah Distance Iterasi ke-2

\begin{tabular}{cc}
\hline Klaster 1 & Klaster 2 \\
\hline 0 & 0 \\
6.359347 & 2.035412 \\
0.979847 & 3.95784 \\
4.761932 & 4.607928 \\
13.06862 & 0.15 \\
1.390863 & 4.972092 \\
5.818978 & 7.805895 \\
3.582094 & 20.6694 \\
4.548758 & 18.82571 \\
& 0.906035 \\
& 3.1637 \\
& 10.58702 \\
& 5.199779 \\
& 7.258278 \\
& 3.228885 \\
& 15.09674 \\
& 18.24133 \\
& 3.17402 \\
& 5.976972 \\
& 1.97952 \\
& 4.05021 \\
& 5.643067 \\
& 0.667308 \\
& 8.067323 \\
& 12.12064 \\
& 168.3850999 \\
& \\
&
\end{tabular}

Dari hasil pejumlahan data diatas distance baru - distance lama menghasilkan simpangan >0,maka proses pengelompokan berhenti pada iterasi kedua dengan hasil simpangan 22.6231132

\section{KESIMPULAN}

Berdasarkan penelitian yang telah dilakukan maka dapat disimpulkan bahwa Algoritma K-Medoid pada proporsi lapangan kerja informal sektor non-pertanian berdasarkan wilayah dapat diterapkan pada penelitian ini. Data yang diolah menjadi 2 cluster yaitu cluster tingkat lapangan kerja rendah $(\mathrm{C} 1)$ dan cluster tingkat lapangan kerja tinggi(C2). Dimana hasil penelitian ini menyimpulkan dari 34 provinsi di indonesia bahwa cluster tingkat lapangan kerja rendah(C1) yaitu, Sumatera Barat, Lampung, Jawa Tengah, Jawa Timur, Nusa Tenggara Barat, Nusa Tenggara Timur, Kalimantan Selatan, Gorontalo dan Sulawesi Barat. Sedangkan cluster tingkat lapangan kerja tinggi(C2) yaitu Aceh, Sumatera Utara, Riau, Jambi, Sumatera Selatan, Bengkulu, Kep.Bangka Belitung, Kep.Riau, DKI Jakarta, Jawa Barat, DI Yogyakarta, Banten, Bali, Kalimanatan Barat, Kalimantan Tengah, Kalimantan Timur, Kalimantan Utara, Sulawesi Utara, Sulawesi Tengah, Sulawesi selatan, Sulawesi Tenggara, Maluku, Maluku Utara, Papua Barat dan Papua.

\section{REFERENCES}

[1] A. A. Noeraini, M. Fakultas, and E. Universitas, "EKONOMI INFORMAL DI INDONESIA, SUATU TINJAUAN PUSTAKA," 2013.

[2] S. P. Pekerja, S. Informal, and A. Kebijakan, "Studi Profil Pekerja di Sektor Informal dan Arah Kebijakan ke Depan 1," pp. $1-18,2002$.

[3] L. Kerja and D. A. N. Perbandingannya, "Kontribusi sektor pertanian dalam penyediaan lapangan kerja dan perbandingannya dengan sektor-sektor lain," pp. 1-15, 1999.

[4] S. M. Dewi and A. P. Windarto, "Analisis Metode Electre Pada Pemilihan Usaha Kecil Home Industry Yang Tepat Bagi 
Mahasiswa," Sist. J. Sist. Inf., vol. 8, no. 3, pp. 377-385, 2019.

[5] D. R. S. P, A. A. Muin, and M. Amin, "PEMILIHAN FACIAL WASH UNTUK KULIT WAJAH BERMINYAK DENGAN METODE PROMETHEE II," CESS (Journal Comput. Eng. Syst. Sci., vol. 4, no. 2, pp. 222-229, 2019.

[6] C. Astria, A. P. Windarto, and Z. Musiafa, "PEMILIHAN PRODUK SAMPO SESUAI JENIS KULIT KEPALA DENGAN METODE PROMETHEE II,” CESS (Journal Comput. Eng. Syst. Sci., vol. 4, no. 2, pp. 178-185, 2019.

[7] D. N. Batubara, A. P. Windarto, and M. R. Raharjo, "PENERAPAN PROMETHEE II PADA PEMILIHAN PRODUK CONDITIONER SEBAGAI UPAYA PENINGKATAN MINAT BELI KONSUMEN," CESS (Journal Comput. Eng. Syst. Sci., vol. 4, no. 2, pp. 191-197, 2019.

[8] D. N. Batubara, D. R. S. P, and A. P. Windarto, "Penerapan Metode PROMETHEE II Pada Pemilihan Situs Travel Berdasarkan Konsumen,” J. SISFOKOM, vol. 8, no. 1, pp. 46-52, 2019.

[9] A. P. Windarto, "Penerapan Datamining Pada Ekspor Buah-Buahan Menurut Negara Tujuan Menggunakan K-Means Clustering Method," Techno.Com, vol. 16, no. 4, pp. 348-357, 2017.

[10] M. G. Sadewo et al., "PENERAPAN ALGORITMA CLUSTERING DALAM MENGELOMPOKKAN BANYAKNYA DESA / KELURAHAN MENURUT UPAYA ANTISIPASI / MITIGASI BENCANA ALAM MENURUT PROVINSI DENGAN K-MEANS,” vol. 2, pp. 311-319, 2018.

[11] H. Siahaan, H. Mawengkang, S. Efendi, A. Wanto, and A. P. Windarto, "Application of Classification Method C4 . 5 on Selection of Exemplary Teachers," in IOP Conference Series, 2018, pp. 1-6.

[12] Sudirman, A. P. Windarto, and A. Wanto, "Data mining tools | rapidminer: K-means method on clustering of rice crops by province as efforts to stabilize food crops in Indonesia," IOP Conf. Ser. Mater. Sci. Eng., vol. 420, p. 12089, 2018.

[13] S. Azhar, H. Latipa, S. Leni, and N. Zulita, "Sistem Pakar Penyakit Ginjal Pada Manusia Menggunakan Metode Forward Chaining," J. Media Infotama, vol. 10, no. 1, pp. 16-26, 2014.

[14] T. Budiharjo, Soemartono, T., Windarto, A.P., Herawan, "Predicting tuition fee payment problem using backpropagation neural network model," Int. J. Adv. Sci. Technol., 2018.

[15] T. Budiharjo, Soemartono, T., Windarto, A.P., Herawan, "Predicting school participation in indonesia using back-propagation algorithm model," Int. J. Control Autom., 2018.

[16] A. P. Windarto, M. R. Lubis, and Solikhun, "MODEL ARSITEKTUR NEURAL NETWORK DENGAN BACKPROPOGATION PADA PREDIKSI TOTAL LABA RUGI KOMPREHENSIF BANK UMUM KONVENSIONAL," Kumpul. J. Ilmu Komput., vol. 5, no. 2, pp. 147-158, 2018.

[17] A. P. Windarto, M. R. Lubis, and Solikhun, "IMPLEMENTASI JST PADA PREDIKSI TOTAL LABA RUGI KOMPREHENSIF BANK UMUM KONVENSIONAL DENGAN BACKPROPAGATION," J. Teknol. Inf. dan Ilmu Komput., vol. 5, no. 4, pp. 411-418, 2018.

[18] Sumijan, A. P. Windarto, A. Muhammad, and Budiharjo, "Implementation of Neural Networks in Predicting the Understanding Level of Students Subject,” Int. J. Softw. Eng. Its Appl., vol. 10, no. 10, pp. 189-204, 2016.

[19] "Implementasi Algoritma K-modes untuk Penentuan Prioritas Rehabilitasi Daerah Aliran Sungai Berdasarkan Parameter Lahan Kritis," pp. 429-440, 2017.

[20] L. Maulida, P. Studi, and M. Informatika, "KUNJUNGAN WISATAWAN KE OBJEK WISATA UNGGULAN DI PROV . DKI JAKARTA DENGAN K-MEANS," vol. 2, no. 3, pp. 167-174, 2018.

[21] B. Di and C. Com, "K-MODES CLUSTERING UNTUK MENGETAHUI JENIS MASAKAN DAERAH YANG POPULER PADA WEBSITE RESEP ONLINE ( STUDI KASUS : MASAKAN,” vol. 4, no. 4, pp. 290-296, 2017. 